\title{
EFEKTIVITAS METODE PEMBELAJARAN BEYOND CENTERS AND CIRCLE TIME UNTUK PERKEMBANGAN ANAK USIA 5-6 TAHUN
}

\author{
Nurul Hayati a, , Umu Da'watul Choiro ${ }^{\mathrm{b}, 2}$ \\ ${ }^{a, b}$ Institut Agama Islam Nahdatul Ulama Tuban, Indonesia \\ ${ }^{1}$ nurulnyill37@gmail.com, ${ }^{2}$ umu.choir@gmail.com
}

\begin{tabular}{l}
\hline Informasi artikel \\
\hline Received : \\
September 072021. \\
Revised : \\
Sepember 12, 2021. \\
Publish : \\
September 23, 2021. \\
Kata kunci: \\
Pembelajaran Beyond \\
Centers and Circle \\
Tim); \\
Perkembangan Anak \\
Usia Dini; \\
Efektivitas \\
Pembelajaran. \\
;
\end{tabular}

Keywords: Beyond Centers and Circle Time Learning; Early Childhood Development; Learning Effectiveness.

ABSTRAK
Tujuan penelitian ini untuk mengetahui pengembangan aspek
perkembangan anak melalui metode pembelajaran sentra. Dengan
rumusan masalah penelitian, Bagaimana pelaksanaan pembelajaran
BCCT dalam perkembangan Anak Usia Dini di RA Muslimat NU 05
Jenu, apa saja aspek perkembangan anak usia dini dalam pelaksanaan
pembelajaran dengan pendekatan BCCT di RA Muslimat NU 05 Jenu,
Bagaimana efektifitas pelaksanaan metode pembelajaran BBCT dalam
perkembangan Anak Usia Dini di RA Muslimat NU 05 Jenu?. penelitian
ini menggunakan metode kualitatif, dengan Jenis pendekatan deskriptif.
Dengan sumber data Kepala Sekolah, Guru, dan Siswa kelompok B RA
Muslimat NU 05 Jenu, hasil dari penelitian ini adalah RA Muslimat NU
05 Jenu mengembangkan 4 sentra yakni, Sentra Persiapan, Sentra Imtaq,
Sentra Seni, Sentra Cooking, dengan tahapan, Pijakan Lingkungan Main,
Pijakan Sebelum Main, Pijakan Selama Main, Dan Pijakan Setelah Main
yang mengembangkan 6 aspek perkembangan yaitu, Perkembangan Nilai
Agama Dan Moral, Kognitif, Fisik Motorik, Sosial Emosional, Bahasa,
Seni. penelitian ini menghasilkan kesimpulan dengan hasil rata-rata
Berkembang Sesuai Harapan pada perkembangan anak yang dinilai
sebagai metode pembelajaran yang baik dan efektif

\section{ABSTRACT}

The purpose of this study was to determine the development of aspects of child development through the central learning method. With the formulation of the research problem, How is the implementation of BCCT learning in Early Childhood Development at RA Muslimat NU 05 Jenu, what are the aspects of early childhood development in the implementation of learning with the BCCT approach at RA Muslimat NU 05 Jenu, How is the effectiveness of the implementation of the BBCT learning method in child development Early Age at RA Muslimat NU 05 Jenu?. This study uses a qualitative method, with a descriptive type of approach. With data sources from Principals, Teachers, and Students of group B RA Muslimat NU $05 \mathrm{Jenu}$, the results of this study are RA Muslimat NU 05 Jenu developed 4 centers namely, Preparation Center, Imtaq Center, Art Center, Cooking Center, with stages, Environmental Footing Play, Foothold Before Play, Foothold During Play, and Foothold After Play which develops 6 aspects of development, namely, the development of religious and moral values, cognitive, physical motor, social emotional, language, art. This research concludes with the average result of Developing According to Expectations in children's development which is considered a good and effective learning method. texts of its articles and allow readers to use them for any other lawful purpose. 


\section{PENDAHULUAN}

Pendidikan adalah kebutuhan pokok setiap individu, karena pentingnya pendidikan pemerintah mewajibkan pendidikan setidaknya 9 tahun. Menurut undangundang Sisdiknas, Pendidikan adalah usaha sadar dan terencana untuk mewujudkan suasana belajar dan proses pembelajaran agar peserta didik secara aktif mengembangkan kreativitas dan segenap potensi yang ada dalam dirinya. Pelaksanaan pendidikan Anak Usia Dini selalu dikaitkan dengan Bermain sambil Belajar karena dunia anak adalah dunia bermain. Sentra dan lingkaran merupakan salah satu pembelajaran yang dirancang pada sebuah pendekatan pengajaran yang proporsional dalam penempatan siswanya. Sentra dan lingkungan dibuat dengan tujuan dapat menjadi media pembelajaran yang asik dan menyenangkan dengan bermain sambil belajar, Proses pembelajaran yang baik untuk anak usia dini sebaiknya menyesuaikan dengan kebutuhan dan perkembangan anak.

Pembelajaran yang dapat dikembangkan pada kegiatan pembelajaran adalah metode sentra dan lingkaran yang merupakan pendekatan pembelajaran yang berpusat pada anak didik, dimana aktivitas pembelajarannya berpusat pada sentra main dan dalam aktivitas lingkaran, Pembelajaran berbasis sentra merupakan pusat kegiatan bermain anak yang diharapkan mampu mengembangkan semua potensi dan perkembangan sesuai dengan tahapan usianya melalui stimulasi terpadu, Penyelenggaraan pembelajaran sentra merupakan strategi yang dihadirkan guru-guru kedalam suasana kelas yang nyata, siswa didorong membuat hubungan dan pengalaman yang di miliki dan dapat menerapkanya dalam kehidupan sehari-hari.

Berdasarkan paparan di atas dapat disimpulkan bahwa pembelajaran anak usia dini sebaiknya dilaksanakan dengan bermain sambil belajar dan menyesuaikan sesuai kebutuhan perkembangan anak, metode sentra adalah metode yang merupakan pendekatan pembelajaran yang dirancang untuk mengembangkan seluruh potensi anak sesuai minat dan bakat anak.

Rumusan masalah penelitian ini, Bagaimana pelaksanaan pembelajaran BCCT dalam perkembangan Anak Usia Dini di RA Muslimat NU 05 Jenu, apa saja aspek perkembangan anak usia dini dalam pelaksanaan pembelajaran dengan pendekatan BCCT di RA Muslimat NU 05 Jenu, Bagaimana efektifitas pelaksanaan metode pembelajaran BBCT dalam perkembangan Anak Usia Dini di RA Muslimat NU 05 
Jenu. Tujuan penelitian ini untuk mengetahui aspek perkembangan anak melalui metode pembelajaran sentra.

Penelitian ini menggunakan jenis penelitian kualitatif, dengan pendekatan penelitian deskriptif. Lokasi penelitian bertempat di RA Muslimat NU 05 Jenu, sedangkan sumber data yang digunakan penelitian ini adalah kata-kata dan tindakan yang diperoleh dari informan yang terkait dalam penelitian, selanjutnya dokumen atau sumber tertulis lainnya merupakan data tambahan, sumber data melalui kepala sekolah, guru, dan siswa kelompok B. Prosedur pengumpulan data menggunakan model Lincoln \& Guba melalui tiga cara yaitu: observasi partisipatif, wawancara, pengkajian dokumen. Sedangkan analisis data menggunakan model Milles dan Huberman yang terdiri dari: 1) pengumpulan data, 2) reduksi data, 3) penyajian data, 4) menarik kesimpulan. Dan validasi data menggunakan Berpedoman kepada Lincoln \& Guba yang meliputi: 1. Kredibilitas (credibility), 2. Keteralihan (tranferability), 3. Ketergantungan (dependability), 4. Kepastian (confirmability). Namun peneliti hanya menggunakan Kepastian (confirmability) hal ini sesuai dengan apa yang terjadi dilapangan.

Pendidikan berasal dari kata "didik" dalam Bahasa Inggris educate, bring up, raise artinya mendidik, mengemukakan, "sedangkan Pendidik disebut educator, dan Pendidikan disebut education" (Echols, 2003:207). Istilah dalam Pendidikan juga sering disebut sebagai pedagogi yang berarti Pendidikan dan pedagogis yang berarti ilmu Pendidikan. Menurut (Ihsan, 2010:1-2) Secara umum Pendidikan adalah suatu usaha manusia untuk menumbuhkan dan mengembangkan potensi-petensi pembawaan, baik secara jasmani maupun rohani yang sesuai dengan nilai-nilai yang ada di dalam masyarakat dan kebudayaan. Secara umum tujuan Pendidikan anak usia dini adalah mengembangkan berbagai potensi yang ada dalam diri anak sejak dini sebagai kesiapan untuk hidup dan dapat menyesuaikan diri dengan lingkunganya (Agus, 2018:40). Secara khusus tujuan Pendidikan usia dini adalah : 1) Agar anak dapat percaya akan adanya Tuhan dan mampu beribadah serta mencintai sesama. 2) Agar anak mampu mengelola keterampilan tubuhnya, termasuk gerakan motorik kasar dan motorik halus, serta mampu menerima rangsangan motorik. 3) Anak mampu menggunakan Bahasa untuk pemahaman Bahasa pasif dan dapat berkomunikasi secara efektif sehingga dapat bermanfaat untuk berfikir dan belajar. 4) Anak mampu berfikir 
logis, kritis, memberikan alasan, memecahkan masalah, dan menemukan hubungan sebab akibat. 5)Anak mampu mengenal lingkungan alam, lingkungan sosial, peranan masyarakat, menghargai keragaman sosial dan budaya serta mampu mengembangkan konsep diri yang positif dan kontrol diri. 6)Anak memiliki kepekaan terhadap irama, nada, berbagai bunyi, serta menghargai karya kreatif. Karakteristik perkembangan Anak Usia Dini ini dapat dilihat dari beberapa ciri khas (Khairi, 2018:23-27), yaitu: 1) Perkembangan jasmani (Fisik Dan Motorik), 2) Perkembangan Kognitif, 3) Perkembangan Bahasa, 4) Perkembangan Berbicara, 5)Perkembangan Emosi, 6) Perkembangan Sosial, 7)Perkembangan Moral, 8) Perkembangan Spiritual.

Sentra berasal dari kata "centre” yang artinya pusat. Centers (Sentra) adalah zona atau area main anak yang dilengkapi seperangkat alat main. Alat main ini berfungsi sebagai pijakan yang diperlukan untuk mendukung perkembangan anak. Dapat dibagi ke dalam tiga jenis permainan, yaitu main sensorimotor (fungsional), main peran, dan main pembangunan. Hal ini dimaksudkan agar merangsang perkembangan anak pada tahapan yang lebih tinggi. Pendekatan ini menggunakan empat pijakan, yaitu pijakan lingkungan bermain, pijakan sebelum bermain, pijakan selama bermain, dan pijakan setelah bermain (Suyadi, 2010:244).

Pendekatan sentra dan lingkaran adalah pendekatan penyelenggaraan Pendidikan Anak Usia Dini yang berfokus pada anak yang dalam proses pembelajaranya berpusat di sentra main dan saat anak dalam lingkaran dengan menggunakan empat jenis pijakan (scaffolding) untuk mendukung perkembangan anak, yaitu (1) pijakan lingkungan main, (2) pijakan sebelum main, (3) pijakan selama main, (4) pijakan setelah main (Latif, 2016:121).

Dr. Pamela Phelps yakni pencetus pembelajaran BCCT (Beyond Centers And Circle Time) mengembangkan sentra kedalam 7 macam yakni sentra persiapan, sentra balok,sentra bermain peran besar, sentra bermain peran kecil, sentra bahan alam, sentra seni dan sentra musik. Sejak diadopsi oleh Indonesia, sekolah Al Falah Ciracas Jakarta Timur binaan yang merupakan sekolah binaan Dr. Pamela Phelps Sentra dikembangkan ke dalam enam sentra yaitu sentra persiapan, sentra balok, sentra bahan alam, sentra seni, sentra main peran besar, sentra main peran kecil, yang kemudian di tambah satu sentra yakni sentra imtaq sehingga menjadi 7 sentra. 
Sebelum pelaksanaan pembelajaran BCCT(Beyond Centers and Circle Time) ada beberapa hal yang harus diperhatikan, pembelajaran BCCT(Beyond Centers and Circle Time) membutuhkan kesiapan yang matang, hal-hal yang harus dipersiapkan untuk melaksanakan pembelajaran BCCT(Beyond Centers and Circle Time) (Sari, 2014:56-60) antara lain: 1) Persiapan, 2) Pelaksanaan, 3) Penataan Lingkungan Main, 4) Penyambutan Anak, 5) Masa Transisi, 6) Main Pembukaan, 7) Kegiatan Awal Bermain, 8) Kegiatan Inti Bermain dimasing-masing Kelompok, 9) Kegiatan Penutup.

Efektivitas berasal dari kata efektif, dalam Kamus Besar Bahasa Indonesia kreatif berarti ada efeknya, atau pengaruhnya. Efektivitas berarti suatu tingkat keberhasilan yang dihasilkan seseorang dengan cara tertentu dengan tujuan yang hendak dicapai. Sedangkan efektivitas pembelajaran menurut Miarso (dalam Bambang Warsita, 2008:287), "pembelajaran yang efektif adalah belajar yang bermanfaat dan bertujuan bagi peserta didik, melalui pemakaian prosedur yang tepat”.

Menurut Dick dan Raiser (dalam Bambang Warsita 2008: 288) "Efektivitas pembelajaran adalah suatu pembelajaran yang memungkinkan peserta didik untuk belajar keterampilan spesifik, ilmu pengetahuan, dan sikap serta membuat peserta didik senang”.

Berdasarkan uraian di atas dapat disimpulkan bahwa efektivitas pembelajaran adalah pembelajaran yang dilakukan dengan dimaksudkan untuk tujuan keberhasilan siswa yang dilakukan sesuai dengan prosedur yang tepat.

\section{METODE}

Jenis penelitian yang digunakan dalam penelitian ini adalah kualitatif, diistilahkan dengan penelitian ilmiah yang menekankan pada karakter alamiah sumber data. Sedangkan penelitian kualitatif menurut (Sukmadinata, 2010:60) yaitu suatu penelitian yang ditujukan untuk mendeskripsikan dan menganalisis fenomena, peristiwa, aktivitas sosial, sikap, kepercayaan, persepsi, pemikiran orang secara individu maupun kelompok. Jenis penelitian ini adalah deskriptif, karena penelitian ini menggunakan pendekatan kualitatif dan termasuk penelitian studi kasus maka hasil penelitian ini bersifat analisis-deskriptif yaitu berupa kata-kata tertulis atau lisan dari perilaku yang diamati terutama terkait dengan bagaimana metode pembelajaran BCCT (Beyond Centers And Circle Time) di RAMuslimat NU 05 Jenu. Lokasi atau objek yang digunakan peneliti. 
Data penelitian dikumpulkan baik lewat instrumen pengumpulan data, observasi, wawancara maupun lewat data dokumentasi Menurut Lofland, sebagaimana yang dikutip oleh Moleong (2013:157) menyatakan bahwa "sumber data utama dalam penelitian kualitatif ialah kata-kata dan tindakan, selebihnya adalah data tambahan seperti dokumen dan lain-lain". Jadi sumber data dalam penelitian ini adalah kata-kata dan tindakan yang diperoleh dari informan yang terkait dalam penelitian, selanjutnya dokumen atau sumber tertulis lainnya merupakan data tambahan.

Prosedur Pengumpulan Data menggunakan model Lincoln \& Guba (1985) melalui tiga cara yaitu: observasi partisipatif, wawancara, pengkajian dokumen. Analisis data dalam penelitian ini peneliti menggunakan analisis data model Milles dan Huberman (1994) yang terdiri dari: 1) pengumpulan data, 2) reduksi data, 3) penyajian data, 4) menarik kesimpulan. dan Validasi Penelitian berpedoman pada Lincoln \& Guba (1985) yang meliputi: 1. Kredibilitas (credibility), 2. Keteralihan (tranferability), 3. Ketergantungan (dependability), 4. Kepastian (confirmability), namun peneliti mencari keabsahan data dengan cara mencari keabsahan data hanya menggunakan kepastian (Confirmability), hal ini sesuai dengan apa yang terjadi dilapangan

\section{PEMBAHASAN}

Hasil penelitian ini akan membahas, pelaksanaan pembelajaran sentra di RA Muslimat NU 05 Jenu, aspek perkembangan anak usia dini dalam pelaksanaan pembelajaran sentrea di RA Muslimat NU 05 Jenu, efektivitas pembelajaran Sentra di RA Muslinat NU 05 Jenu, dengan uraian sebagai berikut :

\section{1) Pelaksanaan Pembelajaran BCCT}

RA Muslimat NU 05 Jenu melaksanakan metode pembalajaran Sentra dengan mengembangkan 4 Jenis sentra, yakni :

1. Sentra Persiapan, Dalam sentra persiapan anak-anak bermain sambil belajar untuk mengembangkan pengalaman keaksaraan dan pengalaman matematika. Pada Sentra persiapan anak difasilitasi permainan yang mendukung untuk pengalaman baca, tulis, hitung dengan cara yang menyenangan dan anak dapat memilih permainan yang diminati, 
Menurut Suryana (2018: 287) yaitu "sentra persiapan merupakan tempat bermail sambil belajar untuk mengembangkan pengalaman keaksaraan dan pengalaman matematika".

2. Sentra Imtaq, Dalam sentra imtaq tempat bermain sambil belajar untuk mengembangkan kecerdasan jamak dimana kegiatan main lebih menitikberatkan pada kegiatan keagamaan. Di sentra imtaq anak difasilitasi dengan kegiatan bermain yang memfokuskan pada pembiasaan beribadah dan mengenal huruf hijaiyah dengan cara bermain sambil belajar, Menurut Akbar (2020:166) Sentra Imtaq adalah "tempat kegiatan beribadah yang disiapkan di dalamnya bermacam-macam perlengkapan ibadah yang bertujuan untuk menanamkan nilai-nilai beragama".

3. Sentra Seni, Sentra seni ini merupakan tempat anak bermain sambil belajar yang menitik beratkan pada kemampuan anak dalam berkreasi. Kegiatan di sentra ini dilaksakan dalam bentuk proyek, dimana anak diajak untuk menciptakan kreasi tertentu yang akan menghasilkan sebuah karya. Dimana anak-anak akan diajak membuat karya yang mungkin belum pernah mereka lakukan sebelumnya, Menurut Tamin (2010:32) sentra seni ini "memberikan kesempatan pada anak untuk terus bereksplorasi dan bereksperimen dengan berbagai bahan dan alat seni”. Dengan mengembakan sentra seni anak-anak diharapkan dapat berfikir secara kreatif.

4. Sentra Cooking merupakan pembelajaran yang lebih difokuskan dalam pengenalan alat-alat yang berupa bentuk, tekstur dan fungsi dari alat masak tersebut, selain mengenalkan anak pada alat-alat masak yang digunakan dalam kehidupan sehari-hari, kegiatan memasak merupakan kegiatan yang menyenangkan dan menjadi kegiatan untuk anak bersosial, tidak hanya itu sentra cooking juga bertujuan untuk mengembangkan motoric halus saat anak melakukan kegiatan seperti memotong, menusuk. "Memasak selalu menjadi kegiatan yang menyenagkan untuk anak, seperti yang aspek nilai kegiatan yang tercermin dalam kopetensi sikap, pengetahuan dan keterampilan yang dapat membuat anak melakukan kegiatan bersama-sama" (Beaty, 2013: 253-254)

Pelaksanaan pembelajaran dengan menggunakan model Sentra yang diterapkan di RA Muslimat NU 05 Jenu merupakan kegiatan bermain yang 
dilakukan dengan bermain memberikan ruang yang luas kepada anak untuk bereksplorasi dan menemukan pengalaman sendiri yang bermakna melalui permainan dan pembelajaran yang telah diberikan, anak-anak mampu mencoba dan melakukan permainan yang mereka sukai yang telah disiapkan guru. Dalam proses pembelajaranya inilah tahapan-tahapan yang dilakukan guru dalam pembelajaran metode sentra :

1. Penataan Lingkungan Main/ Pijakan Lingkungan Main

Dalam penataan lingkungan main/Pijakan Lingkungan Main guru mempersiapkan penataan lingkungan main anak sehari sebelum pembelajaran dilakukan, guru menyiapkan tema yang akan digunakan, menata alat dan bahan main yang akan digunakan sesuai dengan kelompok belajar anak, penataan lingkungan main dilakukan sehari sebelum pembelajaran dengan tujuan saat anak-anak datang semua telah siap untuk dilakukan pembelajaran.

2. Pijakan Sebelum Main

Pijakan lingkungan main dimulai pada pukul 07.30-08.00 dengan kegiatan senam, bernyanyi, bermain, dll. Guru meminta anak untuk membuat lingkaran, lalu mengajak anak untuk memulai permainan, atau bernyanyi, sesudah bermain dan bernyanyi telah usai, guru menanyakan kesiapan anak untuk memulai pembelajaran hari itu sesuai dengan tema, guru melakukan tanya jawab terlebih dahulu tentang apa yang akan dilakukan hari itu, kemudian guru menjelaskan apa yang akan dilakukan hari ini dengan benar dan menjelaskan alat peraga yang akan digunakan. Sesudah penjelasan guru membentuk kelompok untuk melakukan sentra-sentra yang telah dibuat guru. Sesudah membentuk kelompok guru menanyakan juga apa permainan yang ingin mereka mainkan terlebih dahulu, jika dirasa semua sudah memilih guru meminta anak untuk masuk ke sentra yang telah dipilih.

3. Pijakan Selama Main

Pijakan selama main dimulai pada 08.00-09.00, anak dipersilahkan mengerjakan tugas masing-masing densitas sesuai dengan RPPH hari itu yang telah guru buat sebelumnya, pada pijakan ini guru berkeliling melihat anak yang sedang bermain, guru memberikan contoh kepada anak-anak belum bisa menggunakan alat-alat, memberikan dukungan dan pertanyaan positif terkait 
dengan permainan yang sedang anak mainkan, memberi bantuan jika anak membutuhkan bantuan, mencatat semua perkembangan anak selama bermain, memberitahukan setiap saat tinggal berapa waktu yang mereka punya untuk menyelesaikan tugas mereka, kemudian guru mengumpulkan semua tugas yang telah diselesaikan anak.

4. Pijakan Setelah Main.

Pijakan setelah main dimulai pada 09.30-10.15 setelah istirahat, pada pijakan ini guru memberi tahukan anak bahwa permainan hari ini telah selesai dan meminta anak untuk membereskan mainan yang telah digunakan, jadi anak turut dilibatkan dalam membereskan alat dan bahan main. Alat dan bahan main diatur dan di kelompokkan sesuai dengan jenis dan tempatnya, setelah semua mainan telah dibereskan guru mengajak anak membentuk lingkaran, pada saat ini guru mengajak anak berbincang tentang kegiatan yang lakukan pada hari itu, kegiatan apa saja yang dilakukan, bagaimana perasaanya selama bermain, dan juga guru memberi tahu anak tema pembelajaran besok dan kegiatan apa yang akan dilakukan. Terakhir penutupan guru mengajak anak untuk berdo'a bersama sebelum pulang.

\section{2) Aspek Perkembangan}

Pembelajaran 4 sentra yang diterapkan di RA Muslimat NU 05 Jenu yang kesemua sentra saling berhubungan, Berikut ini 6 aspek perkembangan pada pembelajaran dengan menggunakan metode sentra di RA Muslimat NU 05 Jenu :

1. Perkembangan Nilai Agama Dan Moral, kegiatan pengembangan diri yang dipilih dan diterapkan RA Muslimat NU 05 dalam Aspek Perkembangan Nilai Agama dan Moral anak adalah mengenal ibadah kepada Allah SWT, dengan bentuk kegiatan dilaksanakanya baca tulis Al Qur'an, hafalan surat-surat pendek, pengenalan kisah nabi, hafalan Asmaul Husna, hafalan dan do'a niatniat ibadah, praktek ibadah. Menurut (Suryana, 2019:57) "usia dini adalah saat yang paling baik bagi guru untuk meletakkan dasar-dasar pendidikan nilai,moral, dan agama kepada anak usia dini”.

2. Perkembangan Kognitif, RA Muslimat NU 05 bertujuan dapat mengembangkan ide dan kemampuan anak untuk bereksperimen, bentuk kegiatan yang dipilih merupakan kegiatan yang dilaksanakan dengan belajar 
memecahkan masalah, Maka dari itu Guru membantu anak mengembangkan kapasitas berpikir formal dengan menempatkan anak dalam situasi yang menantang pikiran dan menuntut mereka memecahkan masalah tersebut.

3. Perkembangan Bahasa, RA Muslimat NU 05 bertujuan dapat mengembangkan kemampuan anak untuk dapat berkomunikasi dan memahami kalimat dengan baik dan benar dengan bentuk kegiatan bermain peran, bercerita. Menurut Hurlock (1978: 186) perkembangan bahasa anak usia dini ditempuh melalui cara yang sitematis dan berkembang bersama-sama dengan pertambahan usianya. Anak mengalami tahapan perkembangan yang sama namun yang menbedakan antara lain: sosial keluarga, kecerdasan, kesehatan, dorongan, hubungan, dengan teman yang turut mempengahurinya, ini berarti lingkungan turut mempengaruhi perkembangan bahasa anak, lingkugan yang baik maka perkembangan anak akan baik, namun sebaliknya jika tidak maka anak juga akan ikut dalam lingkungan tersebut.

4. Perkembangan Fisik Motorik, perkembangan fisik motorik setiap anak berbeda-beda, setiap perkembangan fisik sangat berkaitan erat dengan motorik anak, perkembangan motorik merupakan pengendalian gerakan-gerakan tubuh melalui kegiatan yang terkoordinasi antara susunan saraf, otot, otak, dan spinal cord. Setiap perkembangan motorik anak sangat di pengaruhi oleh organ otak, semakin matangnya perkembangan system saraf otak yang mengatur otot memungkinkan berkembanganya kompetensi atau kemampuan motorik anak. Hurlock (1978: 159) menyatakan bahwa perkembangan motorik diartikan sebagai perkembangan dari unsur kematangan pengendalian gerak tubuh dan otak sebagai pusat gerak. Gerak ini secara jelas dibedakan menjadi gerak kasar dan halus.

5. Perkembangan Sosial Emosional, tujuan pengembangan Sosial Emosional anak di RA Muslimat NU 05 adalah mengembangkan kemampuan menguasai emosi (pengendalian psikologi anak) untuk dapat bertanggung jawab dan mandiri, menumbuhkan social anak yang tinggi. Suyadi (2010:108) mengatakan bahwa perkembangan social adalah tingkat jalinan interaksi anak dengan orang lain, mulai dari orang tua, saudara, teman bermain, hingga 
masyarakat luas. Sementara perkembangan emosional adalah luapan perasaan ketika anak berinteraksi dengan orang lain.

6. Perkembangan Seni, Perkembangan Seni, Salah satu upaya untuk menjadikan anak mempunyai kemampuan terampil dan kreatif adalah memberikan mereka pelajaran seni. Pelajaran seni terbukti dapat meningkatkan kepandaian berekspresi anak, pemahaman sisi-sisi kemanusiaan, kepekaan dan konsentrasi yang tinggi, serta kreativitas yang gemilang. Menurut Sumanto (2005: 7) menyatakan tentang pengertian seni sebagai berikut: Seni adalah hasil atau proses kerja dan gagasan manusia melibatkan kemampuan trampil, kreatif, kepekaan indera, kepekaan hati dan piker untuk menghasilkan suatu karya yang memiliki kesan keindahan, keselarasan, bernilai seni dan lainnya.

\section{3) Efektivitas Pembelajaran Sentra}

Model pembelajaran sentra berfokus pada bermain dan lingkaran. Pembelajaran BCCT diarahkan untuk dapat merangsang seluruh aspek kecerdasan anak, agar kecerdasannya dapat berkembang secara optimal, maka otak anak perlu dirangsang untuk terus berpikir secara aktif dengan menggali pengalamannya sendiri, Pembelajarannya berpusat pada anak, menempatkan pengaturan lingkungan utama sebagai pijakan awal yang penting, memberikan dukungan penuh kepada setiap anak untuk aktif, kreatif, dan berani mengambil keputusan sendiri, peran guru sebagai fasilitator, motivator, dan evaluator, kegiatan anak berpusat di sentra-sentra main yang berfungsi sebagai pusat minat, yang diharapkan dapat mengembangkan seluruh aspek perkembangan anak dengan maksimal. Banyak sekali keunggulan metode sentra dalam mengembangkan aspek perkembangan anak usia dini, dalam pembelajaranya anak-anak dapat menggali pengalamanya sendiri melalui bermain, mereka akan diberi kebebasan untuk dapat berkreasi sesuai dengan imajinasi mereka sehingga dapat merangsang anak untuk kreatif, dan juga mendapat pengalaman secara nyata.

Selaras dengan pernyataan Muhsinin \& Navi (2017) “(1) Model pembelajarannya tidak memerlukan peralatan yang banyak (2) Mudah untuk merangsang seluruh aspek kecerdasan anak (Multiple Intelegent) melalui bermain yang terarah.(3) Setting pembelajarannya mampu merangsang anak saling aktif,kreatif, dan terus berfikir dengan menggali pengalaman sendiri. (4) 
Memungkinkan anak untuk melakukan manipulasi terhadap berbagai obyek, dapat bereksplorasi, berinteraksi secara fisik,emosional,sosial dan secara kognitif serta kegiatan variatif yang menarik lainnya.(5) Meningkatkan pelayanan pengalaman belajar kepada anak secara lebih mendalam dengan memberikan kebebasan bereksplorasi dalam setiap sentranya. (6) Dapat melatih anak untuk lebih mandiri”. berikut ini merupakan tabel pencapaiam anak dalam perkembangan anak usia dini.

Tabel Indikator Pencapaian Anak Kelompok B1

\begin{tabular}{|l|l|l|l|l|l|l|l|l|}
\hline \multirow{2}{*}{ NO } & \multirow{2}{*}{ NAMA } & \multicolumn{6}{|l|}{ INDIKATOR PENCAPAIAN } & \multirow{2}{*}{ KET } \\
\cline { 3 - 9 } & & $\mathbf{1}$ & $\mathbf{2}$ & $\mathbf{3}$ & $\mathbf{4}$ & $\mathbf{5}$ & $\mathbf{6}$ & \\
\hline 1. & Ilul & BSB & BSH & BSB & BSH & BSH & BSH & BSH \\
\hline 2. & Teguh & MB & MB & BSH & BSH & MB & MB & MB \\
\hline 3. & Radha & BSH & BSH & BSH & MB & MB & BSH & BSH \\
\hline 4. & Mela & BSB & BSH & BSB & BSH & BSB & BSB & BSB \\
\hline 5. & Celyn & BSB & BSB & BSH & BSH & BSH & BSH & BSH \\
\hline 6. & Rani & BSH & BSH & BSH & BSH & BSH & BSH & BSH \\
\hline 7. & Salsa & BSH & BSH & BSH & MB & BSH & BSH & BSH \\
\hline 8. & Aqila & BSB & BSH & BSB & BSH & BSB & BSB & BSB \\
\hline 9. & Hafidz & BSH & MB & MB & BSB & BSH & MB & MB \\
\hline 10. & Syauqi & BSH & MB & BSH & BSH & BSH & MB & BSH \\
\hline 11. & Al & BSH & BSH & BSH & BSB & MB & BSH & BSH \\
\hline 12. & Aiz & BSB & BSH & BSH & BSB & BSH & BSH & BSH \\
\hline 13. & Fatiha & BSB & BSB & BSB & BSB & BSH & BSB & BSB \\
\hline 14. & Ulya & BSB & BSH & BSH & MB & BSB & BSB & BSB \\
\hline 15. & Shanaz & BSB & BSB & BSH & BSB & BSH & BSB & BSB \\
\hline 16. & Azri & BSH & MB & MB & BSH & BSH & BSH & BSH \\
\hline RATA-RATA & BSB & BSH & BSH & BSH & BSH & BSH & BSH \\
\hline
\end{tabular}

\section{Tabel Indikator Pencapaian Anak Kelompok B2}

\begin{tabular}{|l|l|l|l|l|l|l|l|l|}
\hline \multirow{2}{*}{ NO } & \multirow{2}{*}{ NAMA } & \multicolumn{2}{|l|}{ INDIKATOR PENCAPAIAN } & \multirow{2}{*}{ KET } \\
\cline { 3 - 8 } & & $\mathbf{1}$ & $\mathbf{2}$ & $\mathbf{3}$ & $\mathbf{4}$ & $\mathbf{5}$ & $\mathbf{6}$ & \\
\hline 1. & Rara & BSH & BSH & BSH & BSH & BSB & BSH & BSH \\
\hline 2. & Risky & BSH & BSB & BSH & BSH & BSB & BSH & BSH \\
\hline 3. & Anggun & BSH & BSH & BSH & BSH & BSH & MB & BSH \\
\hline 4. & Firna & BSB & BSH & BSH & BSB & BSH & BSH & BSH \\
\hline 5. & Hani & BSH & MB & MB & MB & BSH & BSB & MB \\
\hline 6. & Nayla & BSB & BSH & BSH & BSH & BSH & BSH & BSH \\
\hline 7. & Rahma & MB & BSH & BSH & BSH & MB & BSH & BSH \\
\hline 8. & Veliza & MB & BSH & MB & BSH & BSB & BSH & BSH \\
\hline 9. & Vano & BSH & BSH & BSB & BSH & BSB & BSH & BSH \\
\hline 10. & Rafi & MB & BSH & BSH & BSH & BSH & BSH & BSH \\
\hline 11. & Angga & BSH & BSH & MB & BSH & BSB & BSB & BSH \\
\hline 12. & Ira & BSH & BSH & BSH & BSH & BSB & BSH & BSH \\
\hline 13. & Raisa & BSB & BSH & BSH & BSB & BSB & BSB & BSB \\
\hline 14. & Sabrina & BSH & BSH & BSB & BSH & MB & BSB & BSH \\
\hline 15. & Nada & BSB & BSH & BSB & BSB & BSB & BSB & BSB \\
\hline 16. & Ina & BSH & MB & BSH & BSH & BSH & MB & BSH \\
\hline RATA-RATA & BSH & BSH & BSH & BSH & BSB & BSH & BSH \\
\hline
\end{tabular}




\section{Indikator Pencapaian :}

1. Anak mampu melakukan kegiatan ibadah sehari-hari dengan baik dan benar

2. Anak mampu menggunakan seluruh anggota tubuh secara optimal untuk perkembangan fisik motorik

3. Anak mampu memecahkan masalah secara kreatif

4. Anak mampu memperlihatkan sikap social terhadap orang lain

5. Anak mampu menggunakan dan memahami bahasa secara verbal dan non verbal

6. Anak mampu mengekspresikan diri secara kreatif dan imajinatif.

\section{Keterangan Hasil Penilaian}

BB : Belum Berkembang

MB : Masih Berkembang

BSH : Berkembang Sesuai Harapan

BSB : Berkembang Sangat Baik

Berdasarkan data di atas diketahui bahwa rata-rata perkembangan anak usia dini kelompok B1 dan B2 adalah Berkembangan Sesuai Harapan dengan uraian, kelompok B1 dengan Mulai Berkembang 2 anak, Berkembang Sesuai Harapan 9 anak, dan Berkembang Sangat Baik 5 anak, sedangkan Kelompok B2 dengan Mulai Berkembang 1 anak, Berkembang Sesuai Harapan 13 anak, dan Berkembang Sangat Baik 2 anak. Hal ini menunjukkan bahwa kelompok B1 dan B2 dengan rata-rata perkembangan Berkembang Sesuai Harapan menjadikan pembelajaran dengan metode sentra untuk mengembangkan perkembangan 6 aspek pada usia anak dini dianggap sebagai metode yang efektif digunakan. Pembelajaran denga metode sentra sangat efektif untuk mendukung perkembangan anak usia dini.

Jadi dapat disimpulkan bahwa pembelajaran sentra dianggap sebagai metode yang efektif digunakan dengan keunggulan dalam pembelajaranya anakanak dapat menggali pengalamanya sendiri melalui bermain, mereka akan diberi kebebasan untuk dapat berkreasi sesuai dengan imajinasi mereka sehingga dapat merangsang anak untuk kreatif, dan juga mendapat pengalaman secara nyata, dan 
dapat diperkuat dengan hasil observasi indikator penilaian anak dengan rata-rata anak dapat berkembangan sesuai harapan pada anak kelompok B1 dan B2.

\section{KESIMPULAN}

Berdasarkan hasil penelitian, RA Muslimat NU 05 Jenu dalam metode pembelajaran sentra mengembangkan 4 model sentra yakni, sentar pesiapan, sentra imtaq, sentra seni, dan sentra imtaq, dengan tahapan pembelajaran, pijakan lingkungan main, pijakan sebelum main, pijakan selama main, dan pijakan setelah main. Pembelajaran Sentra di RA Muslimat NU 05 Jenu juga mengembangkan 6 perkembangan aspek Anak Usia Dini yakni, 1) perkembangan Nilai Agama dan Moral, 2) Perkembangan Kognitif, 3) Perkembangan Bahasa, 4) Perkembangan Fisik Motorik

5) Perkembangan Sosial Emosional, 6) Perkembangan Seni. Pembelajaran menggunakan metode sentra dianggap sebagai pembelajaran yang efektif dan baik dengan ditandainya anak dapat perkembang dengan kualifikasi Berkembang Sesuai Harapan.

\section{REFERENSI}

Agus, Zulkifli. 2018. Konsep Pendidikan Islam Terhadap Pendidikan Anak Usia Dini (PAUD). Jurnal tarbiyah, Volume 3(1): 40.

Akbar, Eliyyil. 2020. Metode Belajar Anak Usia Dini. Jakarta: Prenemedia Group Beaty, Janice. 2013. Perkembangan Anak Usia Dini. Jakarta:Kencana

Echols M, John dan Hassan Shadily. 2003. Kamus Indonesia Inggris. Jakarta: Gramedia

Hurlock, Elizabeth B. 1978. Perkembangan Anak. Jakarta: Erlangga

Ihsan, Fuad H. 2005. Dasar-dasar ilmu Kependidikan. Jakarta : P.T. Rineka Cipta.

Khairi, Huznuzziadatul. 2018. Karakteristik Perkembangan Anak Usia Dini dari 0-6 Tahun. Jurnal Warna, Volume 2(2):15-28.

Latif, Mukhtar, dkk. 2016. Orientasi Baru Pendidikan Anak Usia Dini Kencana. Jakarta: Prenemedia Group.

Moleong, Lexy J. 2013. Metode Penelitian Kualitatif. Edisi Revisi. Bandung : PT. Remaja Rosdakarya.

Muhsinin, dan Ilman Navi. 2017. Efektivitas Pembelajaran Sentra di Kecamatan Trowulo Mojokerto. Jurnal program studi PGRA, Volume 3: 107-124.

Sari Citra Selva. 2014. Pelaksanaan Pembelajaran Dengan Pendekatan Beyond Centers And Circle Time (BCCT) Pada Kelompok B di PAUD Assalam Kota Bengkulu. Skripsi. Tidak di terbitkan. Bengkulu. Universitas Bengkulu. 
Sukmadinata. 2010. Metode Penelitian Pendidikan. Bandung : PT. Remaja Rosda Karya.

Sumanto, 2005. Pengembangan Kreatifitas Seni Rupa Anak TK. Jakarta: depdiknas.

Suryana, Dadan. 2018. Pendidikan Anak Usia Dini, stimulasi dan Aspek perkembangan anak. Jakarta: Prenamedia Group.

Tamin, Wismiarti. 2014. Mengapa Syurga Di Bawah Telapak Kaki Ibu. Jakarta:Pustaka Al Falah

Warsita, Bambang. 2008. Teknologi Pembelajaran, Landasan \& Aplikasinya. Jakarta:Rineka. 